The Agriculturists 14(1): 142-150 (2016) ISSN 2304-7321 (Online), ISSN 1729-5211 (Print)

A Scientific Journal of Krishi Foundation

Indexed Journal

Impact Factor: 0.402 (GIF, 2014)

\title{
A Study on English Teaching Standard in Four Agricultural Universities in Bangladesh
}

\author{
Diana Ansarey* \\ Assistant Professor, Department of English, ASA University Bangladesh \\ *Corresponding author and Email: raquelwelsh11@gmail.com
}

Received: 28 April 2016

Accepted: 12 June 2016

\begin{abstract}
This research has investigated the standard of English teaching in different agricultural universities in Bangladesh. Four agricultural universities namely, Bangladesh Agricultural University, Sher-e-Bangla Agricultural University, Sylhet Agricultural University and Bangabandhu Sheikh Mujibur Rahman Agricultural University were considered in this study conducted in 2015-16. A total of 50 students were selected at random and were interviewed with a pre tested questionnaire. As the medium of instruction of their respective programs, English is a supplementary course in the agricultural universities of Bangladesh which aims to prepare the students to encounter global communication challenges. After the completion of graduation and post-graduation, the students make themselves ready to serve in various local and multinational organizations and companies. In the workplace, English requires additional focuses along with students' subjective expertise due to their prime medium of communication in English. In the case of recruitment, employers often suggest them to develop English language proficiency. So, teaching and learning English is worthy, of focus in regard of the agricultural universities. In this study, the researcher has focused on different steps of students' academic affiliation with English which includes students' academic proficiency in English during admission, needs analysis, syllabus design, purposes of the course as ESP, content quality, hours invested, and assessment. This qualitative research was conducted by observation method and questionnaire survey for data collection. The study revealed that a large number of students studied English course who could communicate efficiently with foreign teams visiting Bangladesh. However, many participants had no clear idea about social and business English. They have suggested the universities to focus on student's English proficiency for professional success.
\end{abstract}

Keywords: Syllabus design, ESP, EAP, CLTA, needs analysis

\section{Introduction}

English is now considered as the most influential lingua franca in global village. It is a part and parcel from academic to professional sectors. In academic perspective, English is instructed to prepare the participants in order to overcome global linguistic challenges. It covers both curriculum and syllabus. In professional world, employers often require higher proficiency in English. Organizations, especially multi-national companies, recruit their human resources from communities of language variety. This strategy facilitates organization/s from the level of technical proficiency. As employees have different linguistic backgrounds, they need 
common language to assimilate ideas and activities. English has occupied this position. Effective communication among the employees or maintaining corporate attachment with external organizations requires outstanding performance in English. So participant's strength on academic affiliation with English influences their recruitment and positioning in the respective organizations.

As Bangladesh is an agriculture-oriented country, there are hundreds of companies and organization which are working for the development of the sector. These companies and organizations recruit their employees, generally, from the graduates of the agricultural universities. During assessment, recruiters often notice the weakness in the English Language. A number of applicants have only minimum proficiency in English though they are proficient in technical skills. So, human resource personnel often suggest development of English language proficiency to potential employment. To justify the situation, syllabus design of the universities comes first as the concerning matter. Therefore, the research problem is to determine adequate methods to develop second language acquisition in the classrooms of Agricultural universities. This investigation carries heavy role on education system in agricultural fields, because when HR teams recruit a group of employees to serve in national and international levels, their weakness in English reduces overall performance of the company including negotiations, project adoptions, scholarships for higher studies. The inappropriate recruitment causes loss of money and quality of employee.

This study was conducted to understand the curriculum and syllabus design of academic English in four agricultural universities of Bangladesh. How needs analyses are maintained in these syllabuses and what the implementation level is in classroom are also considered. Needs analysis focuses on both academic and professional perspectives. Data on syllabuses were collected based on observation and survey method. Finally, this paper recommends some possible suggestions that might be subjected to development in those universities.

\section{Methodology}

To conduct the aforementioned investigation, the researcher has to make a base on theoretical issues though some literature. These issues are the parts of pedagogical studies.

\subsection{Curriculum}

According to Candlin (1984) in Nunan (1988), curriculum is the general presentation of "language learning, learning purpose and experience, evaluation, and the role of relationships of teachers and learners". Nunan (1988) categorizes curriculum into two levels: planning and implication.

\subsection{Syllabus}

Syllabus is a narrow view of language learning. Candlin (1984) says that syllabus is specific presentation of language resources that are "more localized and are based on accounts and records of what actually happens at the classroom level as teachers and learners apply a given curriculum to their own situation". In syllabus, contents are graded according to implicational factors emerging originally from curriculum. Nunan (1988) has primarily categorizes syllabus as two types. First one is product-oriented syllabus which focuses on "the knowledge and skills which learners should gain". It has one important category: functionalnotional syllabus. Another one is process oriented syllabus, synonymously used as procedural syllabus, presents the contents which are "organized around tasks, rather than in terms of grammar or vocabulary" (Richards, Platt, and Weber, 1985 in Nunan, 1988).

\subsection{Needs analysis}

Needs analysis is the adoption of "techniques and procedures for collecting information to be used in syllabus design" (Nunan, 1988). It has two streams. First one is learner analysis which uses the data about the participants. It ranges over certain issues of learners, from gender or 
ethnicity to professional status, through a survey. Second is task analysis which refers to the selection of tasks might be applied to the participants as classroom or practical activity concentrating on the issues emerged from learner analysis. The combination of these two factors plays an important role in the assessment of data presented in this article.

\subsection{Communicative Language Teaching Approach (CLTA)}

Communicative Language Teaching Approach (CLTA) is now the most famous content of English Language Teaching (ELT). It basically focuses on four communication skills: listening, speaking, reading and writing. It follows general and minimum, but not zero, grammatical functions for producing linguistic expressions. According to Richards and Rodgers (1986), the purpose of CLTA is "learning to communicate". The syllabus designed for CLTA requires basically the mixture of notion and function. Experts suggest different modules of syllabus in different times. Yalden (1983) demonstrated some major communicative syllabus types. Richards and Rodgers (1986) summarize a modified version of Yalden's classification of the communicative syllabus types (Table 1).

Table 1. Different types of syllabus

\begin{tabular}{ll}
\hline Type & \multicolumn{1}{c}{ Reference } \\
\hline $\begin{array}{l}\text { 1. Structures plus } \\
\text { functions }\end{array}$ & Wilkins (1976) \\
$\begin{array}{c}\text { 2. Functional spiral } \\
\text { around a structural core }\end{array}$ & Brumfit (1980) \\
$\begin{array}{c}\text { 3. Structural, functional, } \\
\text { instrumental }\end{array}$ & Allen (1980) \\
4. Functional & Jupp and \\
& Hodlin (1975) \\
5. Notional & Wilkins (1976) \\
6. Interactional & Widdowson \\
& (1979) \\
7. Task-based & Prabhu (1983) \\
8. Learner-generated & Candlin (1976), \\
& Henner- \\
& Stanchina and \\
& Riley (1978) \\
\hline
\end{tabular}

\subsection{English for Specific Purposes (ESP)}

When English language is taught and learnt for easy-going in particular areas of knowledge, this is termed as ESP. It is "an intensive, focused and planned teaching” (Rahnuma, 2009). It includes "Business English, Technical English, Scientific English, English for medical professionals, English for waiters, English for tourism, English for Art Purposes," English for Academic purposes. (English for Specific Purposes, 2016). In academic purposes, English is designed whether it may serve the academic performance and the covering of professional challenges. In technical institutions, when the medium of instruction is in English, English is taught empirically, as EAP which is the part of ESP. EAP generally deals with the linguistic knowledge, both practical and theoretical, in academic institutional arena.

As Bangladesh is an agriculture-based country, it has five public universities and two private universities in agriculture. To conduct research, researcher has adopted data observation on four public universities including Sylhet Agricultural University, Bangladesh Agricultural University, Bangabandhu Sheikh Mujibur Rahman Agricultural University, and Sher-e-Bangla Agricultural University. Subjective condition during admission for undergraduate program, syllabus status, course choice to students, barriers of curriculum development, students' views and perceptions etc. have been focused at data collection. A total of 50 students were selected and randomly interviewed by a pre tested questionnaire.

\section{Results and Discussion}

\subsection{Admission policy of different agricultural universities}

Admission in these four universities starts with undergraduate program. Each university fixes specific requirements for respective faculties and subjects. This research considered only the admission circular for the latest and last academic session published in their respective 
websites. Admission requirements were assessed following academic session of 2015-16 in aforementioned universities. Among the requirements, university fixes a parameter for some specific subjects in Higher Secondary level, which is the prerequisite for applicants to get admitted, necessary for the completion of graduation. Securing marks of the applicants usually vary according to the university. The data on academic English in Higher Secondary School Certificate (HSC) examination are presented in table 2 .

In Bangabandhu Sheikh Mujibur Rahman Agricultural University, admission manual requires minimum "B" grade in English achieved in Higher Secondary School Certificate examination which is equal to grade point " 3 " out of "5". GPA-3.00 is marked for 50-59 percent of total 100 marks. Sylhet Agricultural University requires minimum grade point 2 in English which is graded as " $\mathrm{C}$ " and marked as 40-49 out of 100. Bangladesh Agricultural University, situated in Mymensingh, requires GPA 3 in Higher Secondary exam. which is equal to 50-59 marks out of 100, graded as "B". On the other hand, Sher-e-Bangla Agricultural University has no specific parameter for English in Higher Secondary examination as the prerequisite of admission procedures.

From the above data, it is clear that out of four universities, two are allowing applicants having minimum 50-59 percent marks in English, one is with 40-49, and last one has no specific requirements.

Another question to be considered as the applicants switch from secondary education to tertiary level, and that is whether it is necessary to focus on previous performance in English? It is a requirement because it measures applicants' fundamental competence in English. Some other non-agricultural universities have faculties and departments in related fields to agriculture, like fisheries and forestry, but their average requirement in English in HSC is 4.00-5.00 which is relatively higher than agricultural universities which acts as a bench mark to admission requirements because the students language proficiency assess their education background.

Table 3. Grading system of HSC examination

\begin{tabular}{ccc}
\hline \multicolumn{3}{c}{ Grading System in HSC } \\
\hline Letter Grade & Class Interval & Grade Point \\
\hline A+ & $80-100$ & 5 \\
A & $70-19$ & 4 \\
A- & $60-69$ & 3.5 \\
B & $50-59$ & 3 \\
C & $40-49$ & 2 \\
D & $33-39$ & 1 \\
F & $00-32$ & 0 \\
\hline
\end{tabular}

Source: Ministry of Education, Bangladesh

Table 2. Requirement of English grade for admission in different agricultural universities

\begin{tabular}{lccccc}
\hline Name of University & $\begin{array}{c}\text { Admission } \\
\text { session }\end{array}$ & Subject & $\begin{array}{c}\text { Required } \\
\text { Minimum } \\
\text { GPA }\end{array}$ & Grade & $\begin{array}{c}\text { Marks } \\
\text { (out of } \\
100)\end{array}$ \\
\hline BSMR Agricultural University & $2015-16$ & English & 3 & B & $50-59$ \\
Sylhet Agricultural University & $2015-16$ & English & 2 & C & $40-49$ \\
Bangladesh Agricultural & $2015-16$ & English & 3 & B & $50-59$ \\
University & 2016 & English & $\begin{array}{c}\text { Not } \\
\text { specified }\end{array}$ & N/A & N/A \\
Sher-e- Bangla Agricultural & & & & & \\
University & & & & & \\
\hline
\end{tabular}


Another point is that when these applicants are successfully enrolling in universities, they experience English as their medium of instruction and evaluation. Proficiency in Higher Secondary level is considered as the basic competency background of students. So proficiency in previous levels is a matter of concern in English language teaching and learning in agricultural universities.

\subsection{Syllabus design of different agricultural universities}

The researcher made an assessment on syllabus design of the universities. The syllabus of Sylhet Agricultural University is formulated on functional-notional syllabus design that is a major stream of product-oriented syllabuses. Functional-notional syllabus is basically based on "realistic learning tasks" that focus on the production of daily-life linguistic needs based on selected framework. In this syllabus the researcher observes that it has two major parts: grammatical and communicative aspects, it incorporates few basic grammatical items including morphological and syntactical items. In the communicative aspects, it demonstrates phonology, and some selective items from social and business English. According to the university authority, the type of teaching and learning may vary as per faculties. Some departments have both theoretical and practical sessions and some have only theoretical sessions.

The English syllabus of Bangladesh Agricultural University includes basic grammatical items and few items from business English. However, the syllabus of Sher-e-Bangla Agricultural University includes the contents based on four communication skills. In "listening" skill it includes different mechanisms of effective listening. In "speaking" skills, some contents of social English along with effective presentations are highlighted. Then "reading" skill includes certain reading strategies like scanning, skimming, identifying word-clusters etc. Finally, "writing" section incorporates business and academic English along with techniques like grammatical formatting, word choices for text according to the context. In Bangabandhu Sheikh Mujibur Rahman Agricultural University, there is no mandatory and specific English course offered to students.

In this section, the researcher presents data on English course offered in four subject universities. Firstly, Needs Analysis is an important issue to discuss. As English is the medium of instruction in these universities, English should be offered as supplementary course. Their needs have two dimensions: academic and professional. For former, students have to master in English in order to complete their academic activities. The activities might cover general study, class lecture, class tests, exams, presentation, preparing thesis or research paper, academic article for journal etc. To perform these purposes, they require basic and advanced English grammar along with ample vocabulary. Linguistic performance decorates their presentation on academic knowledge in assessments. So, the focus here is merely on grammar rather than task based activities.

The latter, professional dimension, denotes how to prepare students so that they can overcome the challenges of competitive professional life. As for writing genre is concerned, it includes application, cover letter, CV, business English (memos), official dealings (joining letter, letter of reference, letter of recommendation, letter of acceptance, letter of rejection, letter of resignation.), competitive writing (translation, instant paragraph/essay on contemporary writings, free-hand writing etc.), and documentation. In "speaking" skill, it includes effective communication using influential languages along with excellent word choices (managing situation and negotiation), social English along with identifying formal and informal situations (greeting, introducing, welcoming, thanking, saying bye/bidding farewell, asking advice/suggestion, giving advice, offering something, inviting, asking for opinion, agreeing, disagreeing, complaining, apologizing, responding to apology etc.), 
interview (preparation, language code, possible interview questions and answers), professional presentation (strategies, preparation and areas of evaluation), dealing with challenging and competitive teams, public speaking etc. For "listening" purpose, professionals have to identify appropriate sound code along with relevant IPA. Every instruction and question should be understood clearly and firmly. These are the possible needs of English as supplementary course.

In these syllabuses, basic grammatical items are focused, but advanced items are silent. Professional skills are incorporated, but superficially .Students must master social and business English, because these skills will allocate a pathway for their zenith of professional success. If these skills are not studied broadly along with students' subjective fields, it weakens their performance in the workplace.

\subsection{Student's views on English course of different agricultural universities}

To assess the views of students on English course and their expectations, a questionnaire survey was conducted among a number of students. The survey offers ten questions and the format follows closed answers. The subjects of the questionnaire are 50 students of four aforementioned universities, among them $22 \%$ of Sylhet Agricultural University, $42 \%$ are from Bangladesh Agricultural University, 14\% from Bangabandhu Sheikh Mujibur Rahman Agricultural University, and 22\% from Sher-eBangla Agricultural University. Age range of subjects is from 19 to 26 , who are studying at different semesters in various levels under different departments. The questions and analyses are presented in table 4.

Table 4. Student views on English course and their expectations

\begin{tabular}{|c|c|c|c|c|c|}
\hline \multirow{2}{*}{$\begin{array}{l}\text { Sl. } \\
\text { No. }\end{array}$} & \multirow{2}{*}{ Question/ Variables } & \multicolumn{4}{|c|}{ Response of respondents } \\
\hline & & Yes & $\%$ Yes & No & $\% \mathrm{No}$ \\
\hline 1. & Have you studied the course on English? & 39 & 78 & 10 & 20 \\
\hline 2. & Did/Do you enjoy the course? & 30 & 60 & 19 & 38 \\
\hline 3. & $\begin{array}{l}\text { Do you think that English is very important for } \\
\text { academic performance? }\end{array}$ & 47 & 94 & 2 & 04 \\
\hline 4. & $\begin{array}{l}\text { Do you think that English is very important for } \\
\text { professional success? }\end{array}$ & 47 & 94 & 1 & 02 \\
\hline 5. & Are you ready for professional/ job field? & 31 & 62 & 19 & 38 \\
\hline 6. & $\begin{array}{l}\text { If you are given an assignment of motivating a team } \\
\text { from England, are you confident that you can persuade } \\
\text { them effectively using English? }\end{array}$ & 26 & 52 & 22 & 44 \\
\hline 7. & Do you know what Social English is? & 30 & 60 & 20 & 40 \\
\hline 8. & Do you know what Business English is? & 18 & 36 & 31 & 62 \\
\hline 9. & $\begin{array}{l}\text { Do you think that your university should more focus on } \\
\text { students' English development? }\end{array}$ & 48 & 96 & 2 & 04 \\
\hline \multirow[t]{2}{*}{10} & $\begin{array}{l}\text { Which one do you think } \\
\text { Technical } \% \text { of }\end{array}$ & $\begin{array}{l}\text { lish } \\
\text { mance }\end{array}$ & $\begin{array}{l}\% \text { of } \\
\text { espondents }\end{array}$ & Both & $\begin{array}{l}\% \text { of } \\
\text { respon- } \\
\text { dents }\end{array}$ \\
\hline & 1 & 3 & 6 & 43 & 86 \\
\hline
\end{tabular}


All universities do not offer English courses. Not all universities make English courses mandatory. The first question demonstrates the overview of the scenario. In responses, 49 participants respond to the question out of 50 . Thirty nine of them have studied the course on English which was $78 \%$. Another $20 \%$ dropped out. The reason of this course drop is the fact of not adopting the course in curriculum /or keeping the course optional.

Regarding enjoying the course, 30 respondents equivalent to $60 \%$ thought that they enjoyed the course where as $38 \%$ thought that they did not enjoy the course who were 19 participants.

In response to question no 3, 94\% participants considered English as very important for academic performance. This number was 47 participants. Another 2 respondents did not consider English as significant in academic performance which was only $4 \%$.

The question about participants' opinion regarding the importance of English in professional success. For the agricultural workplace, employees' success depends on two streams of expertise: technical and linguistic. Here, 94\%, according to 47 response, believe that English is very important for professional success. Another one participant thought that English does not necessary for the workplace.

The question no 5 is basically associated to selfconfidence of participants' skills. Among 50 respondents, $62 \%$ considered themselves ready for professional or the job field. They were 31 participants. Another 38 percent thought that they are not prepared for job yet; it might be due to academic or personal reason.

In question $6,52 \%$ respondents were confident of their self-proficiency in English communication. Another $44 \%$ participants did not feel confident in their speaking skills.
Social English is situational and contextual categorization of speaking. In question 7, among 50 respondents, $60 \%$, which was 30 in number, knew what social English is. Another $40 \%$ did not know about social English.

In question no 8 was about the English proficiency regarding official or terminological use. The table shows that $36 \%$, which is 18 in number, knew what business English is. Another $63 \%$ respondents had no idea of business English. Thus indicating that Agricultural universities are not familiarised with the term ESP. As Business English deals with professional mechanism, variation in this data may matter in workplace performance.

Question 9 showed that, 96 percent respondents suggested that their respective universities ought to focus more on developing English curriculum. Another 4\% thought the current syllabus is serving the purpose..

The final question shows a statistics regarding participants' professional success. Eight percent participants thought that only technical performance causes professional success. However, another 6\% participants considered English as the key to success where as $86 \%$ respondents thought that both criteria are necessary for securing success.

\section{Findings and Recommendations}

The questionnaire deals with teaching, internal learning (academic), external learning (professional), and participants' personal opinions. In data presentation, some issues have emerged based on three categories: positive, negative, and suggestion. From positive perspective, a large number of students have studied English as a course. Among them a number of respondents are able to communicate effectively with foreign teams who frequently come to this country for various business and corporate dealings, but, despite knowing the professional skills, many participants have no clear idea about social and business English. 
Though many of them are ready for professional or job fields, they lack self-confidence in English proficiency. They can understand the fact that English, along with subjective expertise like official responsibilities for which they are assigned in different agricultural sector in agriculture-based organizations or agencies, is additionally associated with their professional success, but they lack, in most cases, in developing required competence. Therefore, they suggest the respective universities to focus more on this communicative skill which is mandatory in every sphere of life, both academic and professional.

From the above analysis, the researcher makes some points of discussion and relevant recommendation. First of all, syllabus design is a matter of crucial concern. Most of the syllabuses are being followed in these universities focusing mostly on notional contents. Some of which are not well suited to the present job market demand as far as syllabus design is concerned.

It is true that students who study in agricultural universities are not subjected to be expert in language, which is a subject of concern and this should more a reason why students should practice and master proficiency General English. From this analysis, a recommendation is drawn: university/ies should categorize the dimensions into two streams. First stream is academic, where the contents will enable students to excellently perform in academic assessments using English as the medium of communication. Secondly which is all about professional communication.. Here students should prepare themselves for outstanding professional performance, where they may master management of strategies for professional skills. That is, the role of English is imperative in both the areas.

Secondly, the researcher would like to focus on admission requirements. Since the study previously mentions that secured grade in Higher Secondary level, is considered as the entry-level requirement at the tertiary level. In four agricultural universities, average eligible marks range in English in Higher Secondary school certificate is $45 \%-55 . \%$. That appears to be poor in terms of standard. To make the range competitive to other public universities in Bangladesh, the researcher would recommend to raise the benchmark which may motivate the learners in this regard.

Thirdly, it is observed that English courses are usually non- credit courses or optional. Education policy makers ought to ponder so as to work decisively by introducing English courses as mandatory as well as credit based which will enhance both their academic and professional skills to a greater extent as well.

Finally, classroom activities should be interesting for learners. As far as language classroom is concerned, functional contents, task based contents, need analysis, role play, cluster conversation could facilitate the learners expectation and also motivate them in every possible way.

\section{Conclusion}

Excellent English proficiency is the ultimate key to success both in academic and professional arena. The above discussion has presented data analysis through some theoretical issues. Participants conveyed their opinion and preliminary suggestions regarding syllabus design and about the importance of English in the workplace.

The analyses, discussions and recommendations echo the fact of developing the existing English teaching system in agricultural universities. To secure a leading position in the job market, development of English with technical proficiency is mandatory. As agricultural universities in Bangladesh are contributing a lot in their respective sectors, they should spread this success and advantage all over the world. In order to get this space, English language course requires global standard where upgraded and sophisticated syllabus design, standard learning method and enjoying class time will facilitate the 
classroom activities. Special courses might be offered to students to develop their communicative skills. As agricultural sector is now part of global village,. Branding of agricultural sector is the demand of the hour. Therefore, both Agriculture and English should run in juxtaposed.

\section{References}

Allen, P. et al. 1983. The communicative orientation of language teaching: Anobservation scheme. In: J. Handscombe. et al. (eds.) On TESOL 1983. Washington DC: TESOL.

Brumfit, C. J. 1980. Problems and Principles in English Teaching. England: Pergamon Press Ltd.

Candlin, C. 1984. 'Syllabus design as a critical process' in C. J. Brumfit (ed.) 1984a.

Hutchinson, T. and Waters, A. 1987. English for Specific Purposes: A Learning-centered Approach. Cambridge: Cambridge University Press.

Jordan, R. R. 1997. English for Academic Purposes: A Guide and Resource Book for Teachers. Cambridge: Cambridge University Press.

Nunan, D. 1988. Syllabus Design. Oxford: Oxford University Press.
Rahnuma, N. 2009. Theory and Practice of Language Teaching: Significance of Needs Analysis in ESP. Harvest, 24(1729-8326), 127-141pp.

Richards, Jack C. and Theodore Stephen Rodgers 1999. Approaches and Methods in Language Teaching. (2nd ed.). Cambridge: Cambridge University Press.

Richards, Jack, John Platt, and Heidi Weber. 1985. Longman dictionary of applied linguistics. Harlow, Essex, England: Longman.

Widdowson, H. G. 1979. Explorations in applied linguistics. Oxford: Oxford University Press.

Wikipedia. 2016. English for specific purposes. Retrieved 18 May, 2016, from https://en.wikipedia.org/wiki/English_for_ specific_purposes.

Wilkins, D. 1976. Notional syllabuses. Oxford: Oxford University Press.

Yalden, J. 1983. The communicative Syllabus: Evolution, Design and Implementation. England: Fergamon Press Ltd. 